\title{
A New Strategy for Highly Sensitive Immunoassay Based on Single-Particle Mode Detection by Inductively Coupled Plasma Mass Spectrometry
}

\author{
Shenghong Hu, a,b Rui Liu, ${ }^{c}$ Sichun Zhang, ${ }^{a}$ Zhi Huang, ${ }^{\text {a,d }}$ Zhi Xing, ${ }^{\text {a }}$ \\ and Xinrong Zhang ${ }^{\mathrm{a}}$ \\ ${ }^{a}$ Department of Chemistry, Key Laboratory for Atomic and Molecular Nanosciences of Education Ministry, \\ Tsinghua University, Beijing, China \\ ${ }^{\mathrm{b}}$ Key Laboratory of Biogeology and Environmental Geology of Ministry of Education, Faculty of Earth \\ Sciences, China University of Geosciences, Wuhan, China \\ ${ }^{c}$ Key Laboratory of Green Chemistry and Technology of Ministry of Education, College of Chemistry, \\ Sichuan University, Chengdu, China \\ ${ }^{\mathrm{d}}$ College of Life Science and Biotechnology, Jinan University, Guangzhou, China
}

A highly sensitive immunoassay is proposed based on time-resolved inductively coupled plasma mass spectrometry with nanoparticles as tags to antibody. Instead of using traditional integral mode detection, the transient signals induced by the flash of ions in the plasma torch from the ionization of nanoparticles tagged on antibody were recorded in a time-resolved mode. Since, under certain conditions, the frequency of transient signals is directly correlated to the concentration of nanoparticle tags, the concentration of nanoparticle-tagged antibodies can be quantified by the frequency of transient signals. With the present instrument setup, gold nanoparticle (Au-NP) tags, as small as about $15 \mathrm{~nm}$ in diameter, can be detected. This protocol is evaluated for a competitive immunoassay and the linear range for $\alpha$-fetoprotein is $0.016-6.8$ $\mu \mathrm{g} / \mathrm{L}$ (between 20 and $80 \%$ inhibition). The limit of quantification is $0.016 \mu \mathrm{g} / \mathrm{L}(20 \%$ inhibition, $\mathrm{IC}_{20}$ ) with a relative standard deviation of $4.2 \%$ (20\% inhibition, 4 replicates) for $\alpha$-fetoprotein. The present strategy provides a sensitive readout method for nanoparticle tags, which is quite promising for numerous applications in immunoassay, DNA hybridization, and other biological analyses. (J Am Soc Mass Spectrom 2009, 20, 1096-1103) (C 2009 American Society for Mass Spectrometry

$\mathrm{V}$ arious highly sensitive methods for detecting trace biomolecules have been established, over the past several years, by using nanoparticles as tags [1-5]. Gold nanoparticles (Au-NPs) are one kind of outstanding nanoparticle tags that have been extensively used in the biological area. Various readout methods have been adopted to detect Au-NP tags including colorimetric [6-9], surface-plasmon resonance [10-14], and electrochemical methods [15] based on their color change during the formation of aggregates, their surface-plasmon oscillation, or electrochemical activity. Au-NP tags can also be detected indirectly by surface-enhanced Raman scattering [16], a quenching effect on fluorescence of various phosphors [17, 18], or enhancement effect on chemiluminescence [19]. Although these above-cited readout methods have their own advantages and features, special physical or chemical properties of nanoparticle materials are required that limit the number

Address reprint requests to Professor Xinrong Zhang, Tsinghua University, Department of Chemistry, Beijing 100084, China. E-mail: xrzhang@chem. tsinghua.edu.cn of available nanoparticle tags for biological applications. A universal readout method for nanoparticle tags will inevitably enlarge the scope of nanoparticle tag candidates.

The use of inductively coupled plasma mass spectrometry (ICP-MS) as a readout method does not require nanoparticles to possess the optical, electric, electrochemical, magnetic, or other special properties since ions from the atoms of the elements are directly detected by this instrument. The nanoparticles tagged on biological molecules could be detected by ICP-MS, which has been demonstrated by Baranov et al. [20], Merkoci et al. [21], and our group [22, 23] in recent years. An important advantage of ICP-MS for nanoparticle detection is that high sensitivity could be obtained because of large quantities of detectable atoms in each nanoparticle tag. Another advantage is reduced matrix effects from other components of the biological sample. Potential multiplexing detection is a distinguishing feature in ICP-MSbased immunoassay since signals from element tags are essentially nonoverlapping and all the elements can be simultaneously ionized at the same condition [24, 25]. 
However, the high sensitivity of the ICP-MS method for detection of nanoparticle tags has not been sufficiently demonstrated in previous works because the nanoparticles were detected by using traditional integral mode detection as that of analytes dissolved in solution. Those methods could only be able to achieve the detection limits of enzyme-linked immunosorbent assay (ELISA) and not as sensitive as time-resolved fluorescence immunoassay (TRFIA), thus limiting their applications in immunoassay, especially in early cancer diagnosis.

The feasibility of using single-particle analysis for nanoparticle suspensions detection by ICP-MS has been studied by Degueldre et al. [26]. The transient signals induced by the flash of ions arising from the ionization of nanoparticles in the plasma torch can be detected and measured by the mass spectrometer individually so long as only one transient appears during a given dwell time. The single-particle ICP-MS analysis has been tested for nanoparticles of $\mathrm{TiO}_{2}, \mathrm{Al}_{2} \mathrm{O}_{3}, \mathrm{ZrO}_{2}, \mathrm{ThO}_{2}$, and $\mathrm{Au}-\mathrm{NPs}$ in water [26-30]. When the nanoparticles were used as tags in bioassay, this single-particle mode ICP-MS analysis affords the possibility of developing highly sensitive immunoassay and nucleic acids analysis strategies [31].

In the present study, a highly sensitive immunoassay has been proposed based on single-particle mode detection by ICP-MS in a time-resolved analysis (TRA) mode with Au-NPs serving as model tags. The behavior of Au-NPs with an average diameter of about 20, 45, and $80 \mathrm{~nm}$ by ICP-MS in the TRA mode has been investigated. The antibodies tagged with Au-NP tags have been quantitatively detected based on the good correlation between the frequency of transient signals and the concentration of antibodies. To illustrate the performance of ICP-MS-based single-particle mode detection to immunoassay, a competitive heterogeneous immunoassay has been carried out for the determination of $\alpha$-fetoprotein with Au-NP-tagged mouse-anti-human $\alpha$-fetoprotein antibody.

\section{Experimental}

\section{Instrument}

An X Series ICP-MS (Thermo Electron Co., Winsford, Cheshire, UK) was used for the present experiments. The instrument was equipped with a glass concentric nebulizer and an impact bead spray chamber for aerosol generation and filtration. The shield torch was used to improve the sensitivity of signal. A Y-piece was constructed in the flow manifold to continuously add the Au-NP suspension into the blank water stream. The flow rates of the water stream and colloid suspension were $0.5 \mathrm{~mL} / \mathrm{min}$. The transient signals, induced by the ionization of Au-NPs in plasma torch, were obtained by ICP-MS operated in TRA mode. Only the isotope of ${ }^{197} \mathrm{Au}$ was monitored in the experiment to maximize the data sampling frequency. The duration of the flash for a single Au-NP was about 200-400 $\mu$ s [32]. Although a shorter dwell time would prolong the dynamic range for each scan and enhance the signal-to-noise for each transient, the dwell time of $10 \mathrm{~ms}$ was chosen, considering that the intrinsic delay time of the instrument for each transient was $0.9 \mathrm{~ms}$. The 60 -s duration for each scan was used throughout the experiments. In all, 6000 data points were acquired for each temporal profile. The instrument was tuned with multielement standard solution (10 $\mu \mathrm{g} / \mathrm{L}$ of $\mathrm{Li}, \mathrm{Co}, \mathrm{In}, \mathrm{Ce}$, and U) for consistent sensitivity and minimum oxide levels; the operating parameters were then optimized by using a $10 \mu \mathrm{g} / \mathrm{L} \mathrm{Au}$ solution. The operating parameters of ICP-MS instrument are listed in Table 1. The intensity of the signal was measured in counts $/ 10 \mathrm{~ms}$ and the pulse frequency was in pulse number $/ \mathrm{min}$.

\section{Reagents}

The $\alpha$-fetoprotein (AFP) was purchased from the Jiangsu Institute of Nuclear Medicine (Wuxi, China). Mouse-antihuman AFP antibody and bovine serum albumin (BSA) were purchased from Bejing Biosynthesis Biothechnology Co. (Beijing, China). Polystyrene 96-well microtiter plates (Nikon, Sino American Biotechnology Co., Beijing, China) were used to perform the immunoreactions. Pure water with a conductivity of $18.2 \mathrm{M} \Omega \mathrm{cm}^{-1}$ was used throughout this experiment.

\section{Preparation of Au-NP Suspension}

Au-NP suspension was prepared according to the literature with a slight modification [33]. Briefly, an appropriate volume of $1 \%$ trisodium citrate was added into a boiling aqueous solution of $\mathrm{HAuCl}_{4}(0.01 \%)$ with vigorous stirring. The solutions were kept at the boil for 10 min. The resulting Au-NP suspension was cooled and stocked in a brown bottle at $4{ }^{\circ} \mathrm{C}$. Three Au-NP suspensions were measured by transmission electron microscopy and the average diameters of 20, 45, and $80 \mathrm{~nm}$, respectively. The calculated particle concentrations of

Table 1. Operating parameters of ICP-MS

\begin{tabular}{lc}
\hline \multicolumn{1}{c}{ Parameter } & Value \\
\hline \hline RF power (W) & 1400 \\
Cool gas flow (L/min) & 13 \\
Auxiliary gas flow (L/min) & 0.8 \\
Nebulizer gas flow (L/min) & 0.85 \\
Sample uptake rate (mL/min) & 0.5 \\
Water stream flow rate (mL/ & 0.5 \\
$\quad$ min) & \\
Torch & Shield torch \\
Cones & Nickel, HPI design \\
Data acquisition mode & Time-resolved analysis (TRA) \\
Dwell time (ms) & 10 \\
TRA duration time (s) & 60 \\
Resoluti on & Standard \\
Analogue detector voltage (V) & 2130 \\
PC detector voltage (V) & 3650 \\
\hline
\end{tabular}


Au-NPs of 20-, 45-, and 80-nm Au-NP suspensions were approximately $5.91 \times 10^{11}, 5.19 \times 10^{10}$, and $9.24 \times 10^{9}$ particles $/ \mathrm{mL}$, respectively. The Au-NP suspensions used for detection were diluted from the stock suspensions with pure water after sonicating for $5 \mathrm{~min}$.

\section{Preparation of Au-NP-AFP Antibody Complex}

AFP antibody-Au-NP complex was prepared according to the literature with a slight modification [34]. Briefly, AFP antibody and Au-NP suspension were adjusted to $\mathrm{pH} 8.2$ with $0.1 \mathrm{~mol} / \mathrm{L} \mathrm{K}_{2} \mathrm{CO}_{3}$ solution. The minimum tagged amount was determined using a flocculation test. The AFP antibody, with $10 \%$ extra amount to the minimum tagged amount, was added to $1 \mathrm{~mL}$ Au-NP suspension with stirring for $10 \mathrm{~min}$ and followed by incubating at room temperature for $1 \mathrm{~h}$. A 1-mL suspension of Au-NP was tagged with $25 \mu \mathrm{g}$ of AFP antibody; $5 \%$ BSA and 1\% polyethylene glycol (PEG, 20 $\mathrm{kDa}$ ) were added to a final concentration of $1 \%$ and $10 \%$ of total volume to avoid the flocculation of Au-NP-AFP antibody complex.

\section{Optimization of Immunoreaction Conditions}

The optimum antigen concentration coated on the microwell plates and the optimum concentration of AuNP-tagged antibody were determined by checkerboard titration. Purified AFP antigen was diluted by buffer ( $0.05 \mathrm{~mol} / \mathrm{L}$ sodium carbonate/bicarbonate, $\mathrm{pH}$ 9.6) to the concentrations of $0.05,0.10,0.25,0.5,1.0,2.5,5.0$, 25.0 , and $50.0 \mathrm{mg} / \mathrm{L} ; 200-\mu \mathrm{L}$ aliquots of each solution were added to the wells of microwell plates separately and incubated at $37^{\circ} \mathrm{C}$ for $1 \mathrm{~h}$ and then overnight at $4{ }^{\circ} \mathrm{C}$. After incubation, the plate was washed three times with phosphate-buffered saline (PBS) washing buffer containing $0.1 \%$ Tween-20 (PBS-T, $\mathrm{pH} 7.4$ ) to remove unbound antigens. The unbound sites were blocked with $200 \mu \mathrm{L}$ of $3 \% \mathrm{BSA}$ in $0.01 \mathrm{~mol} / \mathrm{L}$ Tris-HCl $(1.21$ $\mathrm{g} / \mathrm{L}$ of Tris, $10.10 \mathrm{~g} / \mathrm{L}$ of $\mathrm{NaCl}$, and $0.25 \mathrm{~mL} / \mathrm{L}$ of $\mathrm{HCl}$ ) by incubation at $37^{\circ} \mathrm{C}$ for $1 \mathrm{~h}$. After washing the plate three times with PBS-T, $200 \mu \mathrm{L}$ of the Au-NP-tagged AFP antibody diluted to $0.05,0.5,2.5,5.0,50$, and 500 $\mu \mathrm{g} / \mathrm{L}$ was added to each well of the plates separately and allowed to incubate in the microwells at $25^{\circ} \mathrm{C}$ for $1 \mathrm{~h}$. Then, the plate was washed three times with PBS-T to remove excess Au-NP-tagged AFP antibody. Finally, $250 \mu \mathrm{L}$ of $2 \%$ nitric acid solution was added to each well to release the tags. The $2 \%$ nitric acid denatured the protein but did not dissolve the Au-NPs. The obtained suspensions were diluted to $5 \mathrm{~mL}$ for ICP-MS determination. The optimum antigen and tagged antibody concentrations were obtained based on the frequency of the flashes of ${ }^{197} \mathrm{Au}$ and the concentrations of Au-NPtagged AFP antibody, which was used for further testing of the competitive immunoassay procedures.

\section{Competitive Immunoassay Procedure}

Figure 1 illustrates the general protocol of this competitive assay for the determination of AFP by using $\mathrm{Au}-\mathrm{NP}$ tags. In brief, standard solutions of AFP antigen were diluted to $0.0001,0.001,0.01,0.1,1,10$, and 100 $\mu \mathrm{g} / \mathrm{L} ; 100 \mu \mathrm{L}$ of each solution was added into different wells, followed by the addition of $100 \mu \mathrm{L}$ of $10 \mu \mathrm{g} / \mathrm{L}$ Au-NP-tagged AFP antibody. The solution was incubated for $1 \mathrm{~h}$ at $37^{\circ} \mathrm{C}$. During this incubation, the AFP in the solution competes with the AFP immobilized on the well for binding sites of Au-NP-tagged AFP antibody. The subsequent assay procedures were performed as described earlier.

\section{Data Analysis}

The sensitivity was estimated by the concentration of half-maximal inhibition $\left(\mathrm{IC}_{50}\right)$, which was obtained by plotting a standard inhibition curve as a function of analyte concentrations. Inhibitory concentration (IC) was calculated by the following expression:

$$
I C=100 \times\left[\left(f_{i}-f_{b}\right) /\left(f_{0}-f_{b}\right)\right]
$$

where $f_{b}$ is the frequency of uncoated antigen and named as nonspecific adsorption to protein, $f_{0}$ is the frequency in the absence of competitive antigen, and $f_{i}$ is the frequency with various concentrations of competitive antigen. The concentrations of analyte in the samples were then obtained by interpolation on the standard curve.

\section{Results and Discussion}

Comparing the Signals of $A u-N P s, A u^{3+}$ Solution, and Pure Water

Au-NPs with average size of $45 \mathrm{~nm}$ in diameter were studied to confirm whether a conventional ICP-MS instrument could be used for determination of extremely diluted nanoparticle suspensions in TRA mode. Figure $2 \mathrm{a}-\mathrm{c}$ shows the signals recorded by ICP-MS in TRA mode for Au-NP suspension, $\mathrm{Au}^{3+}$ solution dissolved from the Au-NP suspension, and pure water,

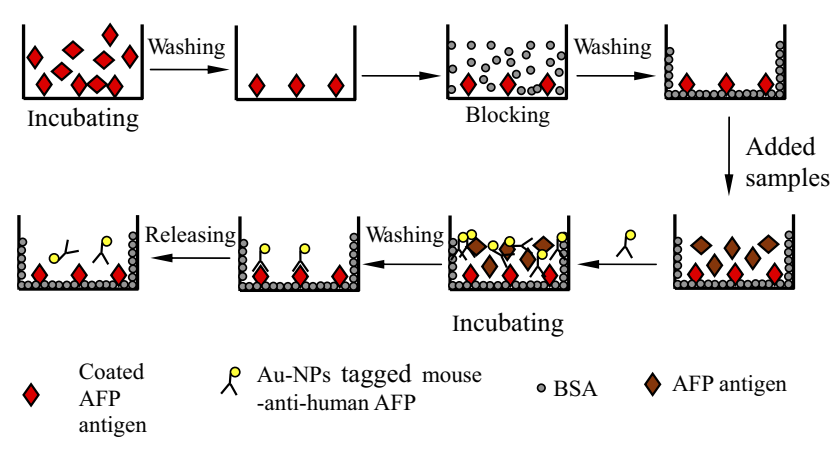

Figure 1. Schematic diagram of the competitive immunoassay for AFP with Au-NP tags. 

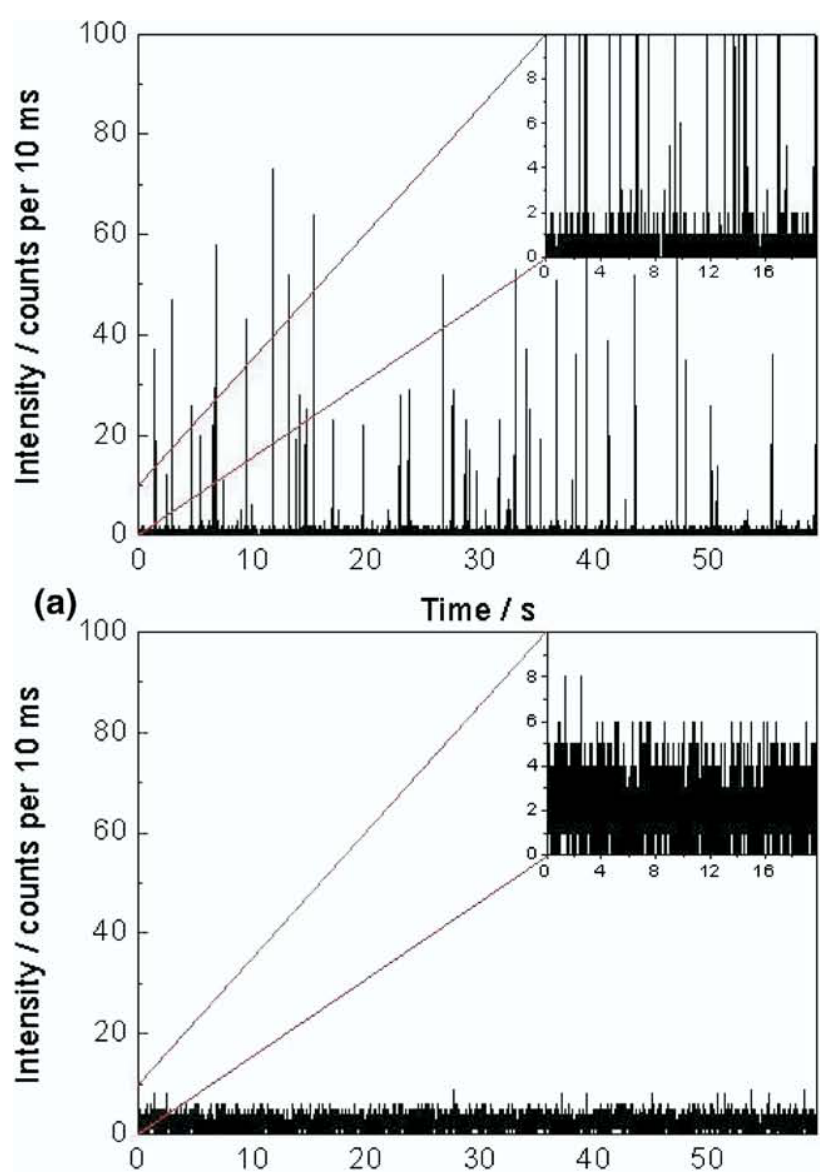

(b)

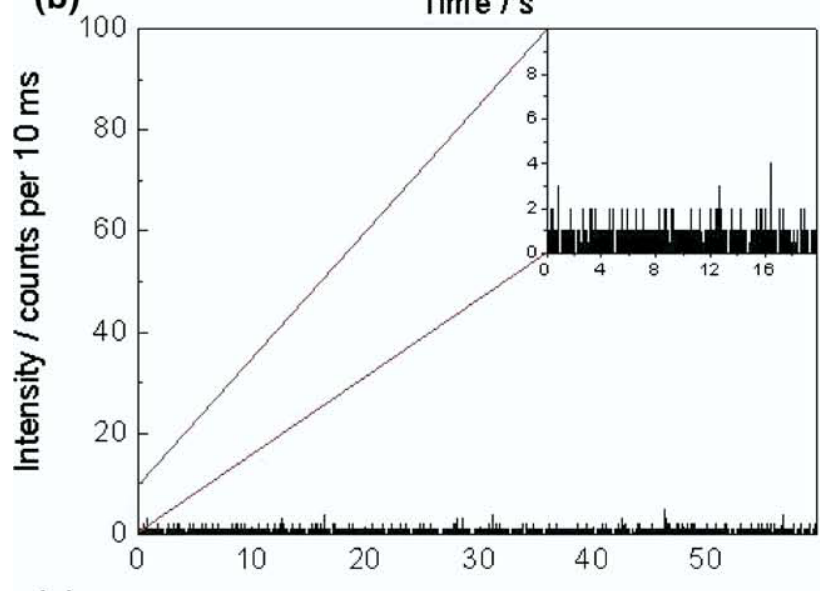

(c)

Time / s

Figure 2. Comparison of the signals obtained by ICP-MS in a time-resolved analysis mode from $\mathrm{Au}-\mathrm{NP}$ suspension, $\mathrm{Au}^{3+}$ solution, and pure water. (a) Au-NP suspension of $45 \mathrm{~nm}$ average size ( $10^{7}$ times dilution of the stock solution, $\sim 5.19 \times 10^{3}$ particles/ $\mathrm{mL})$. (b) $\mathrm{Au}^{3+}$ solution $(20 \mathrm{ng} / \mathrm{L})$. (c) Pure water. Data acquisition mode: time-resolved analysis (TRA). Dwell time: 10 ms. Duration time: $60 \mathrm{~s}$.

respectively. Transient signals from the Au-NP suspension were obviously obtained, as shown in Figure 2a. No obvious pulse signal intensity higher than 10 counts $/ 10$ ms was observed from $\mathrm{Au}^{3+}$ solution (Figure 2b), although the concentration of $\mathrm{Au}$ was higher than that of
$\mathrm{Au}-\mathrm{NP}$ suspension. The reason is that each Au-NP consists of a large number of gold atoms $\left(\sim 2.8 \times 10^{6}\right.$ gold atoms for $45-\mathrm{nm}$ diameter), forming a heterogeneous solution with concentrated gold atoms in different locations of solution. The Au-NP is ionized separately in the plasma torch, forming a flash of ions that can be detected by mass spectrometer in TRA mode. Furthermore, the Au-NP as a single entity is not diluted by the nebulizing gas, thus remaining detectable even with extreme dilution and slight dispersion after atomization. When the solution is extremely diluted, the concentration of the analyte is not sufficient to produce detectable signals because of the limitation of the present ICP-MS instrument, giving only the baseline noise similar to the signals of blank solution (Figure 2c). From the experimental results and the preceding discussion, we concluded that only particles could be detected as transient signals by ICP-MS in TRA mode at extremely low concentration.

\section{Characteristics of the Signals Obtained from $A u-N P s$}

The characteristics of the transient signals obtained from $\mathrm{Au}-\mathrm{NP}$ suspensions at different concentrations were investigated. It was found that the frequency of the transient signals decreased with the dilution of those suspensions, whereas the average intensities of transient signal retained their original counts. As shown in Figure 3a1-a3, the number of the transient signals in $60 \mathrm{~s}$ decreased from 747 to 6 when the suspension of $80 \mathrm{~nm}$ in diameter was diluted from $9.24 \times 10^{4}$ to $9.24 \times 10^{2}$ particles/ $\mathrm{mL}$. However, the average intensities of transient signal remained roughly 190 counts $/ 10 \mathrm{~ms}$ before and after dilution. The invariable signal intensities during the dilution of the suspensions further confirmed that nanoparticles were detected as a single entity. Similar results were also obtained for Au-NP suspensions with the size of 45 and $20 \mathrm{~nm}$ (Figure 3b1-b3, $\mathrm{c} 1$, and $\mathrm{c} 3$ ).

The intensities of transient signals were dependent on the size of Au-NPs and larger Au-NPs gave stronger transient signals, as shown in Figure $3 \mathrm{a}-\mathrm{c}$. The average intensities were 190, 30, and 7 counts $/ 10 \mathrm{~ms}$ for Au-NPs with average size of 80,45 , and $20 \mathrm{~nm}$, respectively. The extraordinarily high transient signals that appeared occasionally during the detection were caused by the aggregation of Au-NPs or multiple particles in one 10-ms measurement period and did not affect the statistical results. The minimum detectable size of an $\mathrm{Au}-\mathrm{NP}$ is around $15 \mathrm{~nm}$ in the present work based on three times the standard deviation of the blank signal. Au-NPs of 20-nm size are close to the detection limit; thus a relatively larger deviation was observed and a miscount of smaller particles in the monodispersed suspension may occur during the detection. Thus a 

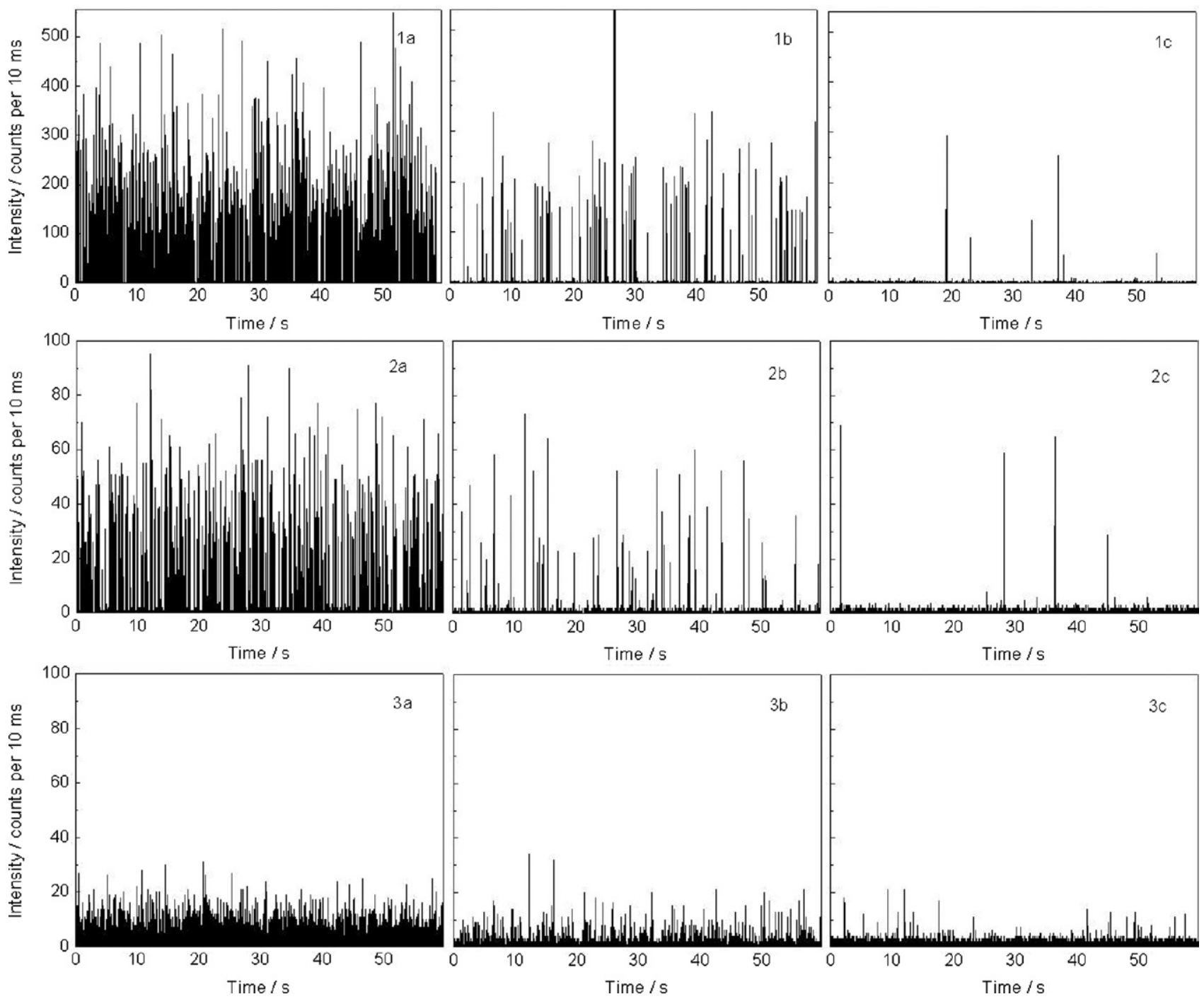

Figure 3. Transient signals obtained from Au-NP with different size and concentration by ICP-MS in TRA mode. (a1) $10^{5}$ times dilution of the stock solution $\left(\sim 9.24 \times 10^{4}\right.$ particles $\left./ \mathrm{mL}\right)$ of an Au-NP suspension with 80-nm average size. (a2) $10^{6}$ times dilution $\left(\sim 9.24 \times 10^{3}\right.$ particles $\left./ \mathrm{mL}\right)$ of an Au-NP suspension with $80-\mathrm{nm}$ average size. (a3) $10^{7}$ times dilution $\left(\sim 9.24 \times 10^{2}\right.$ particles $\left./ \mathrm{mL}\right)$ of an Au-NP suspension with 80-nm average size. (b1) $10^{6}$ times dilution $\left(\sim 5.19 \times 10^{4}\right.$ particles $\left./ \mathrm{mL}\right)$ of an Au-NP suspension with 45-nm average size. (b2) $10^{7}$ times dilution $\left(\sim 5.19 \times 10^{3}\right.$ particles $\left./ \mathrm{mL}\right)$ of an Au-NP suspension with 45-nm average size. (b3) $10^{8}$ times dilution $\left(\sim 5.19 \times 10^{2}\right.$ particles $\left./ \mathrm{mL}\right)$ of an Au-NP suspension with 45-nm average size. (c1) $10^{6}$ times dilution $\left(\sim 5.91 \times 10^{5}\right.$ particles $\left./ \mathrm{mL}\right)$ of an Au-NP suspension with 20-nm average size. (c2) $10^{7}$ times dilution $\left(\sim 5.91 \times 10^{4} \mathrm{particles} / \mathrm{mL}\right)$ of an Au-NP suspension with $20-\mathrm{nm}$ average size. (c3) $10^{8}$ times dilution $\left(\sim 5.91 \times 10^{3}\right.$ particles $\left./ \mathrm{mL}\right)$ of an Au-NP suspension with 20-nm average size. Data acquisition mode: time-resolved analysis (TRA). Dwell time: 10 ms. Duration time: 60 s.

45-nm size of Au-NPs was chosen as the optimum for single-particle detection.

\section{Correlation of Signal Frequency and Concentration of $\mathrm{Au}-\mathrm{NPS}$}

The frequency of the transient signals is proportional to the number concentration of Au-NPs, which could be used as the foundation of a quantitative determination of nanoparticle tags. As shown in Figure 4b, for Au-NPs of $45 \mathrm{~nm}$, the signal numbers in $60 \mathrm{~s}$ were linearly dependent on its number concentration in the range of $5.19 \times 10^{2}$ and $5.19 \times 10^{4}$ particles $/ \mathrm{mL}$, with a correlation coefficient $(\mathrm{R})$ of 0.9999 . As shown in Figure $4 \mathrm{a}$ and c, the linear ranges were from $9.24 \times 10^{2}$ to $9.24 \times 10^{4}$ particles/mL for an Au-NP of $80 \mathrm{~nm}$ with $\mathrm{R}=0.9998$ and from $5.91 \times 10^{3}$ to $5.91 \times 10^{5}$ particles $/ \mathrm{mL}$ for an Au-NP of $20 \mathrm{~nm}$ with $\mathrm{R}=0.9828$. The results indicated that the frequency of transient signals was linearly dependent on the number concentrations of $\mathrm{Au}-\mathrm{NPs}$ in the suspensions. In the present study, as low as $5.19 \times 10^{2}$ particles $/ \mathrm{mL}$ gave about 5 pulses in 


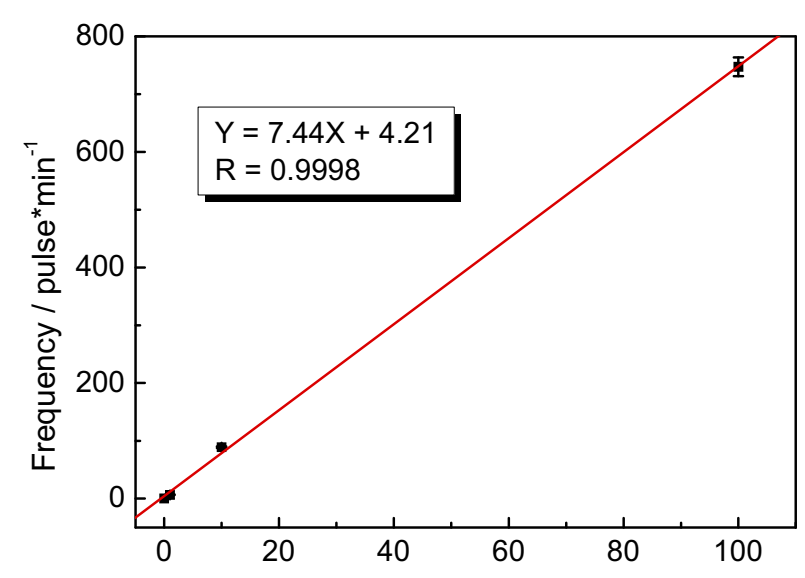

(a) Concentration of Au-NP $/ 9.24^{*} 10^{2}$ particles ${ }^{*} \mathrm{~mL}^{-1}$

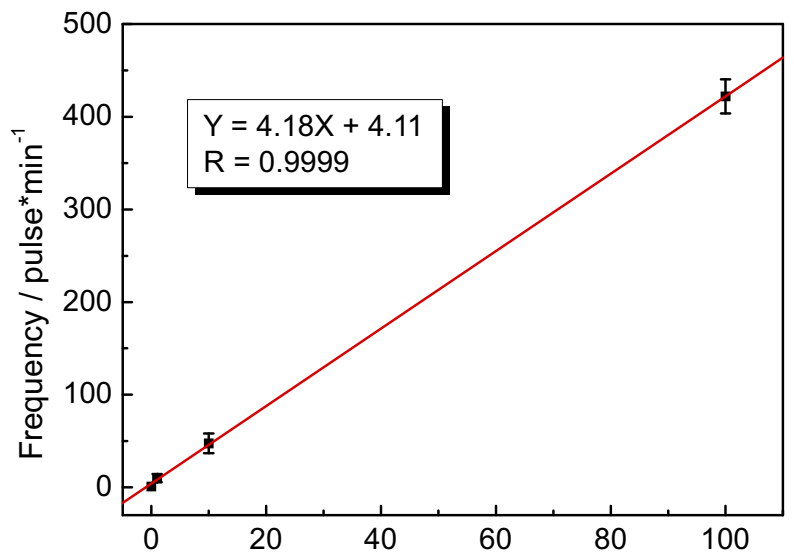

(b) Concentration of Au-NP / 5.19*10 ${ }^{2}$ particles ${ }^{*} \mathrm{~mL}^{-1}$

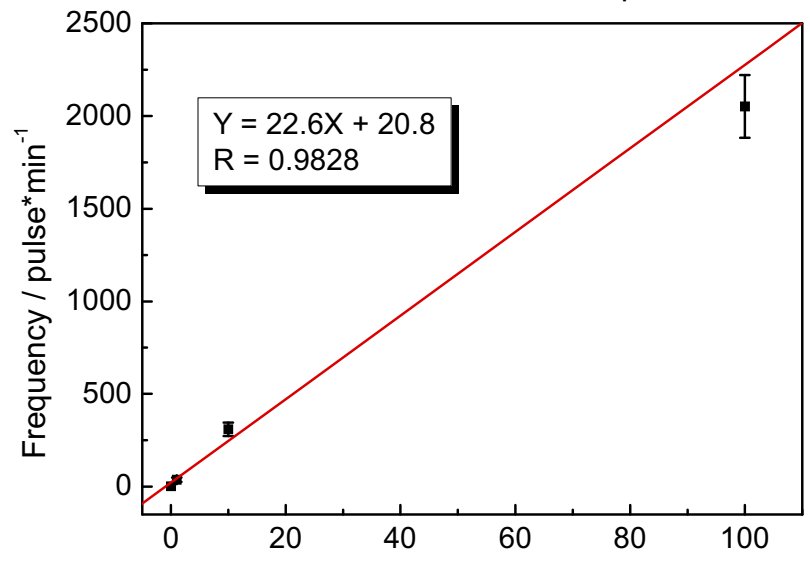

(c) Concentration of Au-NP / 5.91*10 ${ }^{3}$ particles ${ }^{*} \mathrm{~mL}^{-1}$

Figure 4. The frequency of transient signal as a function of number concentration of Au-NP suspension with different size. The sizes of Au-NP were (a) 80, (b) 45, and (c) $20 \mathrm{~nm}$. The concentrations of Au-NP suspension with size of $45 \mathrm{~nm}$ were $5.19 \times$ $10^{4}, 5.19 \times 10^{3}$, and $5.19 \times 10^{2}$ particles $/ \mathrm{mL}\left(10^{6}, 10^{7}\right.$, and $10^{8}$ times dilution of the stock solution). These were $9.24 \times 10^{4}, 9.24 \times 10^{3}$, and $9.24 \times 10^{2}$ particles $/ \mathrm{mL}\left(10^{5}, 10^{6}\right.$, and $10^{7}$ times dilution) for $\mathrm{Au}-\mathrm{NP}$ of $80 \mathrm{~nm}$ and were $5.91 \times 10^{5}, 5.91 \times 10^{4}$, and $5.91 \times 10^{3}$ particles $/ \mathrm{mL}$ $\left(10^{6}, 10^{7}\right.$, and $10^{8}$ times dilution) for Au-NP of $20 \mathrm{~nm}$.

$60 \mathrm{~s}$ with $45-\mathrm{nm}$ size, which means if one particle is detected for a 60-s scan, the Au-NP concentration was around $10^{2}$ particles $/ \mathrm{mL}$.

\section{Optimization of the Immunoassay Conditions}

To optimize the concentration of AFP for coating the microwell plates, a direct immunoassay for a checkerboard titration was performed. Microwell plates were coated with purified AFP antigen with various concentrations and the Au-NP tagged AFP antibody was conjugated directly with the immobilized AFP. Figure 5 shows the effects of AFP concentration for coating on the signal frequencies of various concentrations of Au-NP-tagged AFP antibody. The immunoreactivity of the Au-NPtagged AFP antibodies with the immobilized AFP antigen was characterized by the frequency of flashes of the ${ }^{197} \mathrm{Au}$ signal. The optimal concentration of $5.0 \mathrm{mg} / \mathrm{L}$ for coated AFP antigen was selected for further investigation, considering both sensitivity and reagent-saving.

To optimize the concentration of Au-NP-tagged AFP antibody, a competitive immunoassay was performed in the presence of free AFP at various concentrations. Based on the inhibition curves of AFP antigen with various concentrations of Au-NP-tagged AFP antibodies, the most sensitive assay was obtained using $\mathrm{IC}_{50}$ as a measure. When the immobilized AFP concentration was 5.0 $\mathrm{mg} / \mathrm{L}$, the $\mathrm{IC}_{50}$ for AFP antigen was $0.28,2.3$, and $2.4 \mu \mathrm{g} / \mathrm{L}$ for AFP antibody conjugated with Au-NPs at concentrations of $0.01,0.1$, and $1.0 \mathrm{mg} / \mathrm{L}$, respectively. Therefore, 10 $\mu \mathrm{g} / \mathrm{L}$ of the Au-NP conjugate was selected.

\section{Performance of the Analytical Method}

A competitive immunoassay with different concentrations of AFP standard solutions was carried out. The frequency of the transient signals is inversely proportional to the concentration of AFP in the solution. The inhibition curves for AFP from 0.0 to $1000 \mu \mathrm{g} / \mathrm{L}$ and the error bar were plotted in Figure 6. The working range

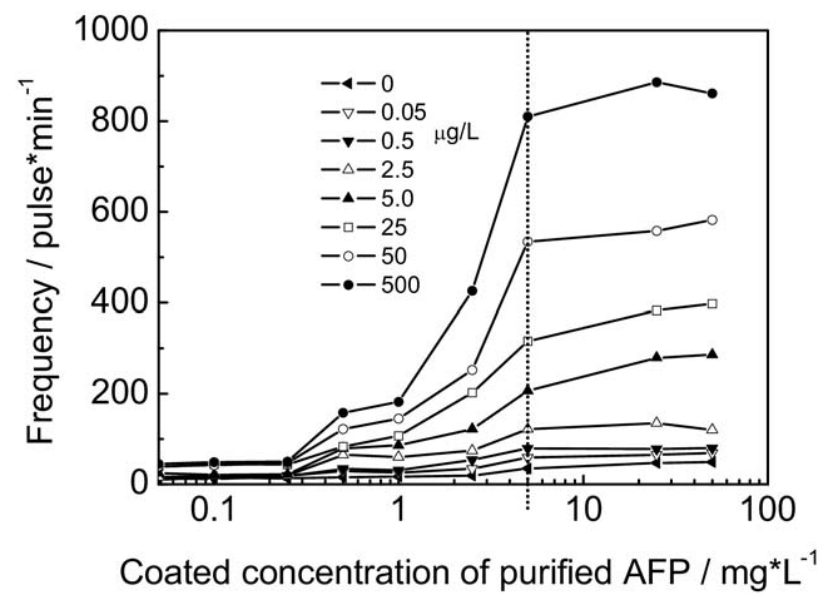

Figure 5. The effects of AFP concentration for coating on the immunoreactivity with various Au-NP-tagged AFP antibody. The concentration of Au-NP-tagged AFP antibody was 0 ([ltrif]), 0.05 $(\nabla), 0.5(\nabla), 2.5(\triangle), 5.0(\bullet), 25(\square), 50(\bigcirc)$, and $500(\bullet) \mathrm{mg} / \mathrm{L}$. The frequency of signal was plotted as a function of coated concentration of purified AFP antigen. The dotted vertical line is the value of $5 \mathrm{mg} / \mathrm{L}$ Au-NP-tagged AFP antibody. 


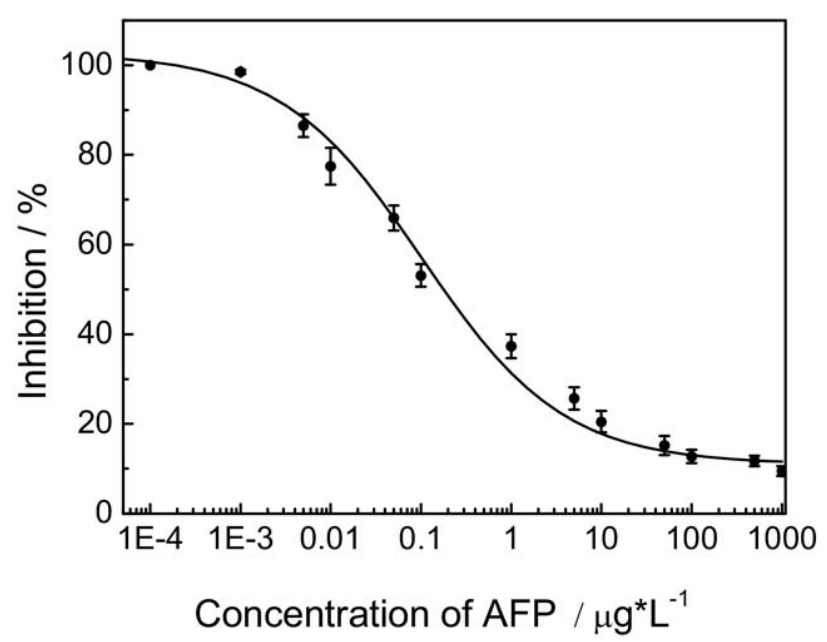

Figure 6. The calibration curves for AFP antigen immunoassay. The standard inhibition was plotted with serially diluted solution of AFP antigen at the concentration of 0.0, 0.0001, 0.001, 0.005, 0.01, $0.05,0.1,1.0,5.0,10,50,100$, and $1000 \mu \mathrm{g} / \mathrm{L} .1 .0 \mathrm{mg} / \mathrm{L}$ AFP antigen for coating and $10 \mu \mathrm{g} / \mathrm{L} \mathrm{Au-NP}$ conjugate AFP antibodies was used for the competition reaction. [The error bars represent confidence intervals of three duplicate detections with confidence level of $95 \%(P=0.05)$.]

was around $0.016-6.8 \mu \mathrm{g} / \mathrm{L}$ (between 20 and $80 \%$ inhibition). The limit of detection, defined as the concentration that produces a $20 \%$ inhibition of the signal $\left(\mathrm{IC}_{20}\right)$, was $0.016 \mu \mathrm{g} / \mathrm{L}$ of AFP. A relative standard deviation (RSD) of $4.2 \%$ can be obtained at $20 \%$ inhibition for four replicates.

A comparison of analytical performance of the present method with that of the other immunoassay methods for the determination of AFP is given in Table 2. It is obvious that the limit of detection in the present method was much lower than that of previous ICP-MS immunoassays. It is also comparable to that of timeresolved fluorescent immunoassay and chemiluminescence immunoassay for the determination of AFP.

\section{Assay of Human Serum Samples}

Sensitive detection of AFP is essential in clinical laboratories because increased levels are associated with a number
Table 3. Analytical results of clinical serum samples

\begin{tabular}{cccc}
\hline & \multicolumn{2}{c}{ This method, $\mu \mathrm{g} / \mathrm{L}$} & \\
\cline { 2 - 3 } Sample & mean $(n=3)$ & RSD $(\%)^{\mathrm{a}}$ & $\mathrm{CL}^{\mathrm{b}} \mu \mathrm{g} / \mathrm{L}$ \\
\hline \hline Serum 1 & 1.36 & 10.3 & 1.54 \\
Serum 2 & 1.88 & 6.9 & 1.98 \\
Serum 3 & 2.88 & 13.2 & 2.83 \\
Serum 4 & 4.71 & 4.9 & 4.84 \\
Serum 5 & 7.48 & 11.4 & 7.86 \\
\hline
\end{tabular}

aRelative standard deviation $(n=3)$.

${ }^{\mathrm{b}} \mathrm{CL}$, chemiluminescence immunoassay was performed by Beijing 301 Hospital.

of conditions including primary hepatocellular carcinoma, nonseminomatous testicular carcinomas, ovarian carcinomas, and other epithelial tumors [35, 36]. Clinical human serum samples were collected from Beijing 301 Hospital (Bejing, China). Results of the proposed method agree with those of clinical chemiluminescent immunoassay, indicating that the present method could be used to determine the AFP with sufficient accuracy and precision (Table 3).

\section{Conclusions}

A new strategy for highly sensitive immunoassay, based on ICP-MS detection in single-nanoparticle mode, has been proposed for the determination of AFP in serum with Au-NP-tagged antibody. In addition to its high sensitivity, the present detection strategy does not necessarily require the nanoparticles to possess special physical or chemical properties, thus extending the availability of nanoparticle tags for biological applications. One of the potentials of the present strategy is that nanoparticles, even single cells tagged with elemental tags, could be detected individually with improved instrument construction. Further development of this method may advance with the realization of simultaneous detection of multiple proteins at extremely low concentration with suitable multiple nanoparticle labels.

Table 2. Comparison of various immunoassay methods for AFP determination ${ }^{a}$

\begin{tabular}{llccc}
\hline \multicolumn{1}{c}{ Tag } & Immunoassay format & Analytical method & Limit of detection $(\mu \mathrm{g} / \mathrm{L})$ & Reference \\
\hline \hline $\mathrm{Au}$ & Microwells/competitive-type & $\begin{array}{c}\text { Single-particle mode ICP immunoassay } \\
\text { with element tagged }\end{array}$ & 0.016 & This method \\
$\mathrm{Eu}^{3+}$ & Microwells/Sandwich-type & ICP-MS immunoassay with element tagged & 0.22 & 20 \\
$\mathrm{Eu}^{3+}$ & Microwells/Sandwich-type & ICP-MS immunoassay with element tagged & 1.2 & 0.07 \\
BHHCT-Eu $^{3+}$ & Microwells/Sandwich-type & Time-resolved Fluoroimmunoassay & 0.042 & 25 \\
BPTA-Tb ${ }^{3+}$ & Microwells/Sandwich-type & Time-resolved fluoroimmunoassay & 0.040 & 37 \\
ALP & Microwells/Sandwich-type & Chemiluminescence immunoassay & 0.07 & 38 \\
ALP & Microwells/Sandwich-type & Amperometric enzyme immunoassay & 2.0 & 40 \\
ITCI & Microwells/Sandwich-type & Electrochemiluminescence immunoassay & 41 \\
\hline
\end{tabular}

${ }^{\mathrm{a}} \mathrm{Au}, \mathrm{Au}$ nanoparticles; BHHCT- $\mathrm{Eu}^{3+}, \mathrm{Eu}^{3+}$ chelate of 4,4'- bis $\left(1^{\prime \prime}, 1^{\prime \prime}, 1^{\prime \prime}, 2^{\prime \prime}, 2^{\prime \prime}, 3^{\prime \prime}, 3^{\prime \prime}\right.$-heptafluoro- $4^{\prime \prime}, 6^{\prime \prime}$-hexanedion-6"-yl)-chlorosulfo-o-terphenyl; BPTA- $\mathrm{Tb}^{3+}, \mathrm{Tb}^{3+}$ chelate of $\mathrm{N}, \mathrm{N}, \mathrm{N}_{1}, \mathrm{~N}_{1}^{\prime}-(2,6$-bis(3'-aminomethyl-1'-pyrazolyl)-4-phenyl pyridine) tetrakis (acetic acid); ALP, alkaline phosphatase; $\mathrm{ITCl}$, isothiocyanato isoluminol. 


\section{Acknowledgments}

This work was supported by Grants 20535020 and 20875053 from the National Natural Science Foundation of China.

\section{References}

1. Klostranec, J. M.; Chan, W. C. W. Quantum Dots in Biological and Biomedical Research: Recent Progress and Present Challenges. Adv. Mater. 2006, 18, 1953-1964.

2. Rosi, N. L.; Mirkin, C. A. Nanostructures in Biodiagnostics. Chem. Rev. 2005, 105, 1547-1562.

3. Michalet, X.; Pinaud, F. F.; Bentolila, L. A.; Tsay, J. M.; Doose, S.; Li, J. J.; Sundaresan, G.; Wu, A. M.; Gambhir, S. S.; Weiss, S. Quantum Dots for Live Cells, In Vivo Imaging, and Diagnostics. Science 2005, 307, 538-544.

4. Katz, E.; Willner, I. Integrated Nanoparticle-Biomolecule Hybrid Systems: Synthesis, Properties, and Applications. Angew. Chem. Int. Ed. 2004, 43, 6042-6108.

5. Niemeyer, C. M. Nanoparticles, Proteins, and Nucleic Acids: Biotechnology Meets Materials Science. Angew. Chem. Int. Ed. 2001, 40, 41284158.

6. Elghanian, R.; Storhoff, J. J.; Mucic, R. C.; Letsinger, R. L.; Mirkin, C. A. Selective Colorimetric Detection of Polynucleotides Based on the DistanceDependent Optical Properties of Gold Nanoparticles. Science 1997, 277, 1078-1081.

7. Hou, S. Y.; Chen, H. K.; Cheng, H. C.; Huang, C. Y. Development of Zeptomole and Attomolar Detection Sensitivity of Biotin-Peptide Using a Dot-Blot Gold nanoparticle Immunoassay. Anal. Chem. 2007, 79, 980-985.

8. Thanh, N. T. K.; Rosenzweig, Z. Development of an Aggregation-Based Immunoassay for Anti-Protein A Using Gold Nanoparticles. Anal. Chem. 2002, 74, 1624-1628.

9. Taton, T. A.; Mirkin, C. A.; Letsinger, R. L. Scanometric DNA Array Detection with Nanoparticle Probes. Science 2000, 289, 1757-1760.

10. Driskell, J. D.; Kwarta, K. M.; Lipert, R. J.; Porter, M. D. Low-Level Detection of Viral Pathogens by a Surface-Enhanced Raman Scattering Based Immunoassay. Anal. Chem. 2005, 77, 6147-6154.

11. Yu, C.; Irudayaraj, J. Multiplex Biosensor Using Gold Nanorods. Anal. Chem. 2007, 79, 572-579.

12. Lin, H. Y.; Chen, C. T.; Chen, Y. C. Detection of Phosphopeptides by Localized Surface Plasma Resonance of Titania-Coated Gold Nanoparticles Immobilized on Glass Substrates. Anal. Chem. 2006, 78, 6873-6878.

13. Lyon, L. A.; Musick, M. D.; Natan, M. J. Colloidal Au-Enhanced Surface Plasmon Resonance Immunosensing. Anal. Chem. 1998, 70, 5177-5183.

14. He, L.; Musick, M. D.; Nicewarner, S. R.; Salinas, F. G.; Benkovic, S. J.; Natan, M. J.; Keating, C. D. Colloidal Au-Enhanced Surface Plasmon Resonance for Ultrasensitive Detection of DNA Hybridization. J. Am. Chem. Soc. 2000, 122, 9071-9077.

15. Dequaire, M.; Degrand, C.; Limoges, B. An Electrochemical Metalloimmunoassay Based on a Colloidal Gold Label. Anal. Chem. 2000, 72, 5521-5528.

16. Driskell, J. D.; Kwarta, K. M.; Lipert, R. J.; Porter, M. D. Low-Level Detection of Viral Pathogens by a Surface-Enhanced Raman Scattering Based Immunoassay. Anal. Chem. 2005, 77, 6147-6154.

17. Li, H. X.; Rothberg, L. J. DNA Sequence Detection Using Selective Fluorescence Quenching of Tagged Oligonucleotide Probes by Gold Nanoparticles. Anal. Chem. 2004, 76, 5414-5417.

18. Ao, L. M.; Gao, F.; Pan, B. F.; He, R.; Cui, D. X. Fluoroimmunoassay for Antigen Based on Fluorescence Quenching Signal of Gold Nanoparticles. Anal. Chem. 2006, 78, 1104-1106.

19. Fan, A. P.; Lau, C. W.; Lu, J. Z. Magnetic Bead-Based Chemiluminescent Metal Immunoassay with a Colloidal Gold Label. Anal. Chem. 2005, 77, $3238-3242$.

20. Baranov, V. I.; Quinn, Z.; Bandura, D. R.; Tanner, S. D. A Sensitive and Quantitative Element-Tagged Immunoassay with ICPMS Detection. Anal. Chem. 2002, 74, 1629-1636.
21. Merkoci, A.; Aldavert, M.; Tarrason, G.; Eritja, R.; Alegret, S. Toward an ICPMS-Linked DNA Assay Based on Gold Nanoparticles Immunoconnected through Peptide Sequences. Anal. Chem. 2005, 77, 6500-6503.

22. Zhang, C.; Zhang, Z. Y.; Yu, B. B.; Shi, J. J.; Zhang, X. R. Application of the Biological Conjugate between Antibody and Colloid Au Nanoparticles as Analyte to Inductively Coupled Plasma Mass Spectrometry. Anal. Chem. 2002, 74, 96-99.

23. Hu, S. H.; Zhang, S. C.; Hu, Z. C.; Xing, Z.; Zhang, X. R. Detection of Multiple Proteins on One Spot by Laser Ablation Inductively Coupled Plasma Mass Spectrometry and Application to Immuno-Microarray with Element-Tagged Antibodies. Anal. Chem. 2007, 79, 923-929.

24. Quinn, Z. A.; Baranov, V. I.; Tanner, S. D.; Wrana, J. L. Simultaneous Determination of Proteins Using an Element-Tagged Immunoassay Coupled with ICP-MS Detection. J. Anal. At. Spectrom. 2002, 17, 892-896.

25. Zhang, S. C.: Zhang, C.; Xing, Z.; Zhang, X. R. Simultaneous Determination of Alpha-Fetoprotein and Free Beta-Human Chorionic Gonadotropin by Element-Tagged Immunoassay with Detection by Inductively Coupled Plasma Mass Spectrometry. Clin. Chem. 2004, 50, 1214-1221.

26. Degueldre, C.; Favarger, P. Y. Colloid Analysis by Single Particle Inductively Coupled Plasma-Mass Spectroscopy: A Feasibility Study Colloids Surf. A 2003, 217, 137-142.

27. Degueldre, C.; Favarger, P. Y.; Rossé, R.; Wold, S. Uranium Colloid Analysis by Single Particle Inductively Coupled Plasma-Mass Spectrometry. Talanta 2006, 68, 623-628.

28. Degueldre, C.; Favarger, P. Y.; Bitea, C. Zirconia Colloid Analysis by Single Particle Inductively Coupled Plasma-Mass Spectrometry. Anal. Chim. Acta 2004, 518, 137-142.

29. Degueldre, C.; Favarger, P. Y. Thorium Colloid Analysis by Single Particle Inductively Coupled Plasma-Mass Spectrometry. Talanta 2004, 62, 1051-1054.

30. Degueldre, C.; Favarger, P. Y.; Wold, S. Gold Colloid Analysis by Inductively Coupled Plasma-Mass Spectrometry in a Single Particle Mode. Anal. Chim. Acta 2006, 555, 263-268.

31. Scheffer, A.; Engelhard, C.; Sperling, M.; Buscher, W. ICP-MS as a New Tool for the Determination of Gold Nanoparticles in Bioanalytical Applications. Anal. Bioanal. Chem. 2008, 390, 249-252.

32. Tanner, S. D.; Ornatsky, O.; Bandura, D. R.; Baranov, V. I. Multiplex Bio-Assay with Inductively Coupled Plasma Mass Spectrometry: Towards a Massively Multivariate Single-Cell Technology. Spectrochim. Acta B 2007, 62, 188-195.

33. Verkleij, A. J.; Leunissen, J. L. M. Immuno-Gold-Labeling in Cell Biology; CRC Press: Boca Raton, FL, 1989.

34. Ni, J.; Lipert, R. J.; Dawson, G. B.; Porter, M. D. Immunoassay Readout Method Using Extrinsic Raman Labels Adsorbed on Immunogold Colloids. Anal. Chem. 1999, 71, 4903-4908.

35. Chan, D. W.; Sell, S. In Teitz Textbook of Clinical Chemistry, 3rd ed.; Burtis, C. A.; Ashwood, E. R., Eds.; W. B. Saunders Co.: Philadelphia, PA, 1999; pp 722-749.

36. O'Riordan, T. C.; Soini, A. E.; Soini, J. T.; Papkovsky, D. B. Performance Evaluation of the Phosphorescent Porphyrin Label: Solid-Phase Immunoassay of Alpha-Fetoprotein. Anal. Chem. 2002, 74, 5845-5850.

37. Matsumoto, K.; Yuan, J.; Wang, G.; Kimura, H. Simultaneous Determination of Alpha-Fetoprotein and Carcinoembryonic Antigen in Human Serum by Time-Resolved Fluoroimmunoassay. Anal. Biochem. 1999, 276 , 81-87.

38. Yuan, J.; Wang, G.; Majima, K. Synthesis of a Terbium Fluorescent Chelate and Its Application to Time-Resolved Fluoroimmunoassay. Anal. Chem. 2001, 73, 1869-1876.

39. Kokado, A.; Tsuji, A.; Maeda, M. Chemiluminescence Assay of Alkaline Phosphatase Using Cortisol-21-Phosphate as Substrate and Its Application to Enzyme Immunoassays. Anal. Chim. Acta 1997, 337, 335-340.

40. DellaCiana, L.; Bernacca, G.; DeNitti, C.; Massaglia, A. Highly Sensitive Amperometric Enzyme Immunoassay for Alpha-Fetoprotein in Human Serum. J. Immunol. Methods 1996, 193, 51-62.

41. Zhuang, H.; Wang, Q.; Chen, G.; Huang, J.; Lin, P. Label of AFP Antibody and Electrochemiluminescence Immunoassay. Chem. Res. Chinese Univ. 1999, 20, 1194-1199. 